\title{
A DFT+U Study On The Structural And Electronic Properties Of BeZnO alloys
}

\author{
Deping Xiong ${ }^{1, \mathrm{a}}$, Miao He $\mathrm{H}^{1, \mathrm{~b}}$, Qu Wang ${ }^{1, \mathrm{c}}$, Zuyong Feng ${ }^{1, \mathrm{~d}}$ \\ ${ }^{1}$ School of Physics and Optoelectronic Engineering, Guangdong University of Technology, \\ Guangzhou, 510006, China

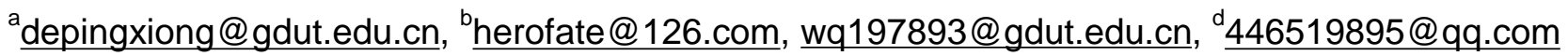

\section{Keywords: BeZnO, DFT $+U$, bowing parameter}

Abstract. The structural and electronic properties of BeZnO alloys were investigated by $\mathrm{DFT}+U$ method, the $U_{\mathrm{o}, \mathrm{p}}=10.2 \mathrm{eV}$ for $\mathrm{O} 2 \mathrm{p}$ and $U_{\mathrm{Zn}, \mathrm{d}}=1.4 \mathrm{eV}$ for $\mathrm{Zn} 3 \mathrm{~d}$ were obtained as the Hubbard $U$ values, using this $U$ values the calculated band-gaps of $\mathrm{ZnO}$ and $\mathrm{BeO}$ are well consistent with the experimental values. The lattice constant $a$ and $c$, total energies, band-gaps as well as formation enthalpies were calculated for $\mathrm{Be}_{x} \mathrm{Zn}_{1-x} \mathrm{O}$ alloys with $\mathrm{Be}$ concentration varying from 0 to 0.375 . The calculated lattice constants comply with the Vegard's law well, and the band-gap bowing parameter is about $5.2 \mathrm{eV}$, the formation enthalpies exhibit a net increase with Be concentration increasing, higher formation enthalpies imply it is more difficult for higher Be doping level.

\section{Introduction}

Zinc oxide $(\mathrm{ZnO})$ is a wide direct band-gap semiconductor material, and has attracted much attention due to its promising applications in ultraviolet (UV) optoelectronic devices in recent years. ${ }^{[1]}$ To produce high efficiency $\mathrm{ZnO}$-based optoelectronic devices, it is necessary to develop $\mathrm{ZnO}$-based heterostructure and quantum well, for fabrication of these structures, ZnO-based alloys were studied in theories and experiments by many researches ${ }^{[2-6]}$. S. Gowrishankar et al. incorporated $\mathrm{Cd}$ or $\mathrm{Mg}$ into $\mathrm{ZnO}$ to tune the band-gap of $\mathrm{MgZnO}$ and $\mathrm{CdZnO}$ alloys ${ }^{[7]}$, Deping Xiong et al. reported that the band-gap of $\mathrm{Mg}_{\mathrm{x}} \mathrm{Zn}_{1-\mathrm{x}} \mathrm{O}$ would be increased up to $3.90 \mathrm{eV}$ when $\mathrm{x}=0.3 .{ }^{[8]}$ However, with $\mathrm{Mg}$ or $\mathrm{Cd}$ concentration increasing, the phase segregation may occur for $\mathrm{MgZnO}$ or $\mathrm{CdZnO}$ alloys due to the large lattice mismatch ${ }^{[9]}$. Recently Ryu et al. prepared $\mathrm{Be}_{\mathrm{x}} \mathrm{Zn}_{1-\mathrm{x}} \mathrm{O}$ films on $\mathrm{Al}_{2} \mathrm{O}_{3}$ substrate by hybrid beam deposition (HBD), Be concentration varied from $0 \%$ to $100 \%$ without phase segregation $^{[10]}$, they even used $\mathrm{Be}_{\mathrm{x}} \mathrm{Zn}_{1-\mathrm{x}} \mathrm{O} / \mathrm{ZnO}$ as active layer to fabricate UV light emitting diodes (LEDs) ${ }^{[11]}$, these indicated that $\mathrm{BeZnO}$ alloys are also an excellent candidate for fabricating $\mathrm{ZnO}$-based devices. Presently, the knowledge on the properties of $\mathrm{BeZnO}$ alloys is still limit and even contradictory, for example, Mingming Chen et al. reported $\mathrm{BeZnO}$ alloys with intermediate Be concentration ( 0.5) were hard to acquire and separated into at least two phases with different Be concentration ${ }^{[12]}$. Therefore, it is necessary to investigate the structural and electronic properties of $\mathrm{BeZnO}$ alloys entirely.

In this work we calculated the lattice constants,band-gaps,total energies and formation enthalpies of $\mathrm{BeZnO}$ alloys with $\mathrm{Be}$ concentration ranging from 0 to 0.375 , the calculations were based on the density functional theory (DFT). However, standard DFT method will underestimate the band gap due to its limitations ${ }^{[13]}$. S.F.Ding et al. investigated the electronic structure of $\mathrm{Be}_{x} \mathrm{Zn}_{1-x} \mathrm{O}$ alloys, the calculated band-gaps of $\mathrm{ZnO}$ and $\mathrm{BeO}$ were found to be only $0.971 \mathrm{eV}$ and $7.320 \mathrm{eV}^{[14]}$, which are far smaller than the experimental values of $3.37 \mathrm{eV}$ and $10.6 \mathrm{eV}$. The DFT $+U$ method attempts to make up for the limitation by using an orbital dependent term added to the DFT potential, the impact of $U$ parameter on the properties of $\mathrm{ZnO}$ have been studied by many researches ${ }^{[15,16]}$. Therefore, we adopted the DFT $+U$ method in this study.

\section{Methods and models}

The present calculations were carried out using the CASTEP software based on DFT ${ }^{[17]}$, in which electron-ion interactions were modeled by ultrasoft pseudopotentials, the generalized gradient 
approximation (GGA) was used to describe the exchange-correlation energy between electrons. To simulate wurtzite $\mathrm{Be}_{\mathrm{x}} \mathrm{Zn}_{1-\mathrm{x}} \mathrm{O}$ alloys with various $\mathrm{Be}$ concentration, we constructed 32 aotm $\mathrm{Be}_{\mathrm{n}} \mathrm{Zn}_{16-\mathrm{n}} \mathrm{O}_{16}$ supercells as shown in Fig.1, which is corresponding to $2 \times 2 \times 2$ primitive unit cell, the corresponding doping level is $0,0.0625,0.125, \ldots$ with $n=0,1,2, \ldots$ The valence atomic configurations were $3 \mathrm{~d}^{10} 4 \mathrm{~s}^{2}$ for $\mathrm{Zn}, 2 \mathrm{~s}^{2} 2 \mathrm{p}^{4}$ for $\mathrm{O}$, and $2 \mathrm{~s}^{2}$ for $\mathrm{Be}$, respectively. The wave functions of the valence electrons were expanded by a plane-wave basis set with the cutoff energy set to $380 \mathrm{eV}$. k-point grid sampling in the supercells was set at $4 \times 4 \times 2$. The convergence threshold was set at $10^{-6} \mathrm{eV}$ for self-consistent iterations. In the optimization process, changes in energy were set at $10^{-5} \mathrm{eV} / \mathrm{atom}$, maximum force and maximum stress were set $0.03 \mathrm{eV} / \AA$ and $0.05 \mathrm{GPa}$, and maximum displacement tolerance was set $0.001 \AA$.

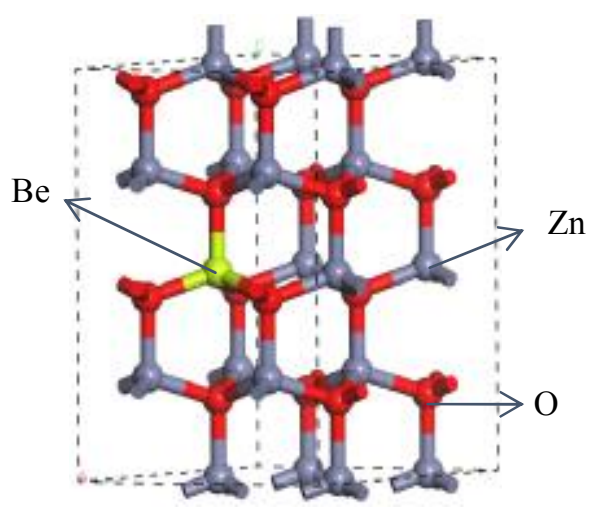

Fig.1 The 32-atom $\mathrm{Be}_{1} \mathrm{Zn}_{15} \mathrm{O}_{16}$ supercell.

To provide the properties of BeZnO alloys more accurately, we employed DFT $+U_{\mathrm{p}}+U_{\mathrm{d}}$ method, $U$ is an important parameter and includes both $p$ states and $d$ states. By setting $U_{\mathrm{Zn}, \mathrm{d}}=10.5 \mathrm{eV}$ and $U_{\mathrm{O}, \mathrm{p}}=7.0 \mathrm{eV}$, Sheetz et al. obtained $3.30 \mathrm{eV}$ for the band-gap of $\mathrm{ZnO}$, which is well consistent with the experimental value of $3.37 \mathrm{eV}^{[18]}$. However, the calculated band-gap of $\mathrm{BeO}$ is $9.47 \mathrm{eV}$ using $U_{\mathrm{O}, \mathrm{p}}=$ $7.0 \mathrm{eV}$, which is still much smaller than the experimental value of $10.6 \mathrm{eV}$. Therefore, in this
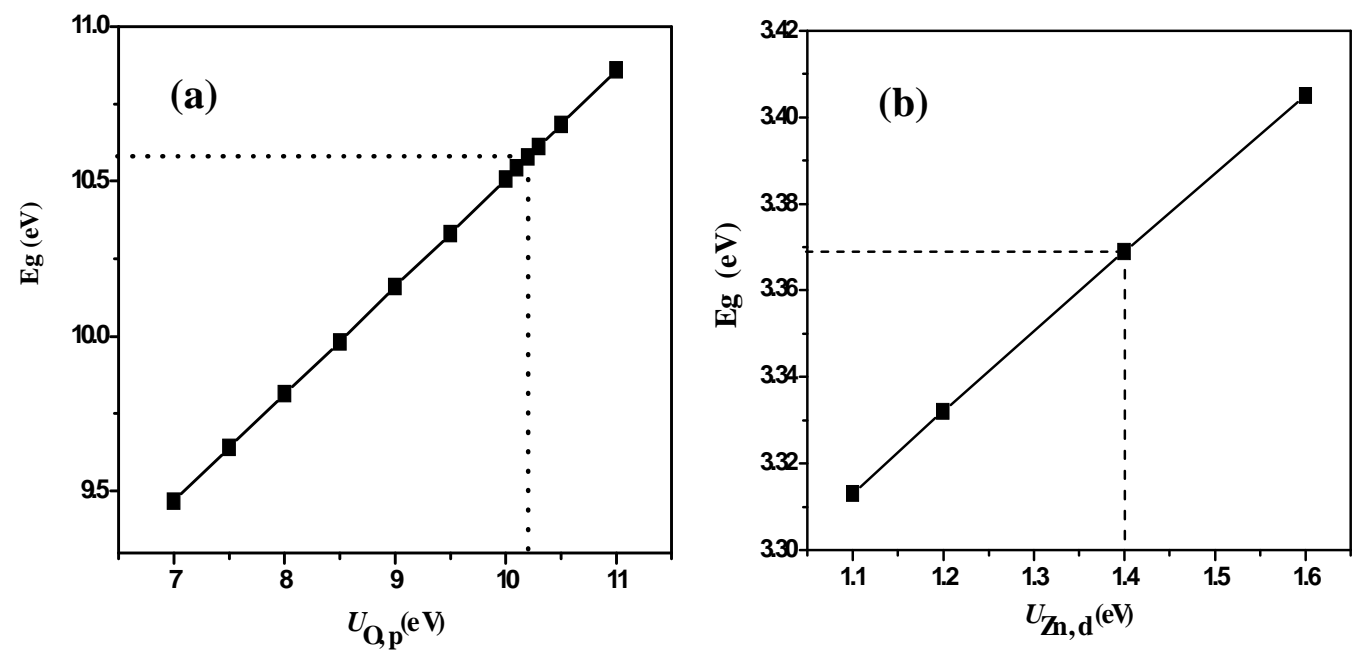

Fig.2 The relationship between the value of $U$ and the band-gap of $\mathrm{BeO}$ and $\mathrm{ZnO}$. (a) the band-gap of $\mathrm{BeO}$ dependent on $U_{\mathrm{O}, \mathrm{p}}$; (b) the band-gap of $\mathrm{ZnO}$ dependent on $U_{\mathrm{Zn}, \mathrm{d}}$.

calculation we re-optimized both $U_{\mathrm{d}}$ for $\mathrm{Zn} 3 \mathrm{~d}$ and $U_{\mathrm{p}}$ for $\mathrm{O} 2 \mathrm{p}$. Fig.1 shows the relationship between the band-gap of wurtzite $\mathrm{BeO}$ and $\mathrm{ZnO}$ with the value of $U$. When $U_{\mathrm{O}, \mathrm{p}}=10.2 \mathrm{eV}$, the calculated band-gap of $\mathrm{BeO}$ is $10.58 \mathrm{eV}$, which is close to the experimental value of $10.6 \mathrm{eV}$, as shown in Fig.1(a). 
Therefore, we fixed $U_{\mathrm{O}, \mathrm{p}}=10.2 \mathrm{eV}$ and changed $U_{\mathrm{Zn}, \mathrm{d}}$ from $1.1 \mathrm{eV}$ to $1.6 \mathrm{eV}$ as shown in Fig.1(b), when $U_{\mathrm{Zn}, \mathrm{d}}=1.4 \mathrm{eV}$, the calculated band-gap of $\mathrm{ZnO}$ is $3.369 \mathrm{eV}$, which is agreed well with the experimental value of $3.37 \mathrm{eV}$. Therefore, $U_{\mathrm{O}, \mathrm{p}}=10.2 \mathrm{eV}$ and $U_{\mathrm{Zn}, \mathrm{d}}=1.4 \mathrm{eV}$ were adopted as the $U$ values in this study.

\section{Results and discussion}

Both $\mathrm{ZnO}$ and $\mathrm{BeO}$ crystal has the same wurtzite structure, the lattice constant of $\mathrm{ZnO}$ is $a=$ $3.249 \AA$ and $c=5.206 \AA$, while it is $a=2.718 \AA$ and $c=4.409 \AA$ for $\mathrm{BeO}^{[17]}, \mathrm{Be}_{\mathrm{x}} \mathrm{Zn}_{1-\mathrm{x}} \mathrm{O}$ has wurtzite structure in the whole range. Firstly, we optimized $\mathrm{Be}_{\mathrm{n}} \mathrm{Zn}_{16-\mathrm{n}} \mathrm{O}_{16}$ supercells and obtained the lattice constants $a$ and $c$, the total energies with various Be concentration. Due to the same Be concentration having several supercell configurations, to determine the preferred configuration, as an example in this calculation, all the possible configurations of $\mathrm{Be}_{2} \mathrm{Zn}_{14} \mathrm{O}_{16}$ supercell were listed in Table 1, the results illustrate that the calculated results vary in a small range for different configurations, and the average values are close to that calculated by the configuration having large weight. Therefore, the large weight configuration was used to study the structural and electronic properties of $\mathrm{Be}_{\mathrm{x}} \mathrm{Zn}_{1-\mathrm{x}} \mathrm{O}$ alloys $(0 \leq x \leq 0.375)$.

Table 1 The calculated lattice constants, band-gaps, as well as total energies for $\mathrm{Be}_{2} \mathrm{Zn}_{14} \mathrm{O}_{16}$ supercell with different configurations.

\begin{tabular}{cccccccc}
\hline \multirow{2}{*}{$\begin{array}{c}\text { Be atom coordinates } \\
\text { Symmetry }\end{array}$} & Weight & $a$ & $c$ & \multicolumn{2}{c}{$\begin{array}{c}\text { Lattice constant }(\AA) \\
(\mathrm{eV})\end{array}$} & $\begin{array}{c}\text { Total } \\
\text { energy } \\
(\mathrm{eV})\end{array}$ \\
\hline$(1 / 3,2 / 3,1 / 4),(1 / 3,1 / 6,1 / 2)$ & $\mathrm{pm}$ & 3 & 3.174 & 5.112 & 3.657 & -31008.80 \\
$(1 / 3,2 / 3,1 / 4),(2 / 3,1 / 3,1 / 2)$ & $\mathrm{cm}$ & 9 & 3.172 & 5.096 & 3.680 & -31008.96 \\
$(1 / 3,2 / 3,1 / 4),(1 / 3,1 / 6,3 / 4)$ & $\mathrm{p} 3 \mathrm{~m} 1$ & 3 & 3.172 & 5.089 & 3.739 & -31009.17 \\
\hline & & Average & 3.172 & 5.098 & 3.687 & -31008.97 \\
\hline
\end{tabular}

Table 2 listed the calculated lattice constant $a$ and $c$, band-gaps, total energies, and formation enthalpies for $\mathrm{Be}_{x} \mathrm{Zn}_{1-x} \mathrm{O}$ alloys. When $x=0$ and 1 typifies $\mathrm{ZnO}$ and $\mathrm{BeO}$, respectively, we obtained their lattice constants are $a=3.233 \AA$ and $c=5.181 \AA$ for $\mathrm{ZnO}, a=2.739 \AA$ and $c=4.434 \AA$ for $\mathrm{BeO}$, which are well consistent with the experimental values of $a=3.249 \AA$ and $c=5.206 \AA, a=2.698 \AA$ and $c=4.409 \AA$ for $\mathrm{ZnO}$ and $\mathrm{BeO}$, respectively. The calculated lattice constant $a$ and $c$ were plotted in Fig. 3 as a function of Be concentration $(0 \leq x \leq 0.375)$, together with the corresponding experimental values. Obviously, doping of Be results in a linear decrease for lattice constant of $a$ and $c$, which is due to the fact that the ionic radius of $\mathrm{Be}^{2+}$ is smaller than that of $\mathrm{Zn}^{2+}$. We fitted the lattice constants in Fig.3 linearly and compared with the experimental values, they have very small deviation from experimental values and comply with the Vegard's law well.

Table 2 Calculated lattice constants $a$ and $c$, band-gap $E_{\mathrm{g}}$, total energy $E_{\mathrm{t}}$, and formation enthalpy $E_{\mathrm{f}}$ for $\mathrm{Be}_{\mathrm{x}} \mathrm{Zn}_{1-\mathrm{x}} \mathrm{O}$ alloys.

\begin{tabular}{ccccccccc}
\hline$x$ & 0 & 0.0625 & 0.125 & 0.1875 & 0.250 & 0.3125 & 0.375 & 1 \\
\hline$c(\AA)$ & 5.181 & 5.159 & 5.096 & 5.059 & 5.015 & 4.965 & 4.887 & 4.441 \\
$a(\AA)$ & 3.233 & 3.199 & 3.172 & 3.139 & 3.104 & 3.085 & 3.032 & 2.745 \\
$E_{\mathrm{g}}(\mathrm{eV})$ & 3.369 & 3.516 & 3.687 & 3.894 & 4.208 & 4.393 & 4.823 & 10.578 \\
$E_{\mathrm{t}}(\mathrm{eV})$ & -34365.5 & -32687.2 & -31009.0 & -29330.8 & -27652.8 & -25974.6 & -24295.9 & -7522.7 \\
$E_{\mathrm{f}}(\mathrm{meV} /$ atom $)-$ & 20.0 & 37.5 & 51.9 & 62.2 & 80.0 & 110.6 & - \\
\hline
\end{tabular}




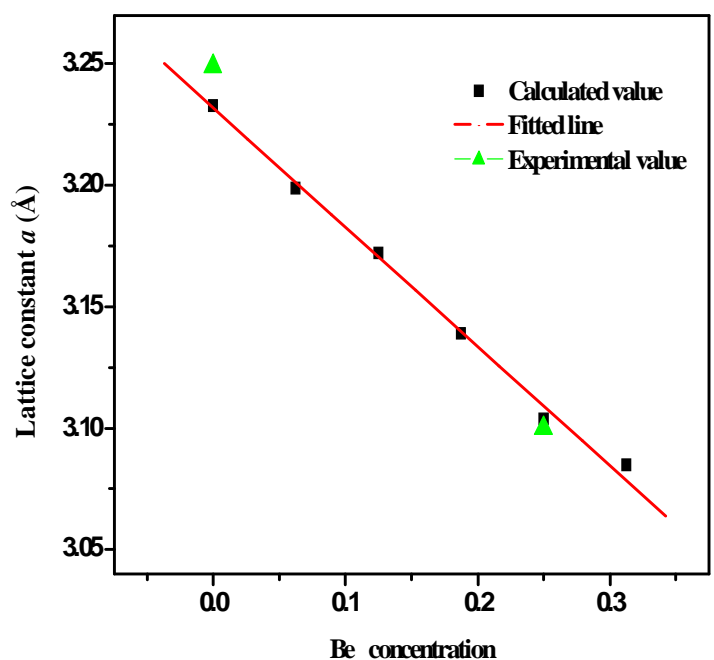

(a)

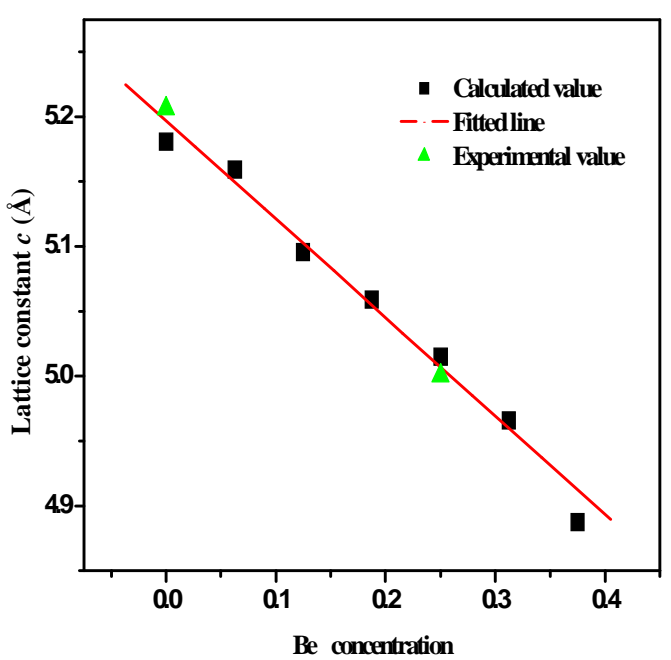

(b)

Fig. 3 The calculated lattice constants, (a) $a$ and (b) $c$, of $\mathrm{Be}_{x} \mathrm{Zn}_{1-x} \mathrm{O}$ alloys with Be concentration ranging from 0 to 0.375 .

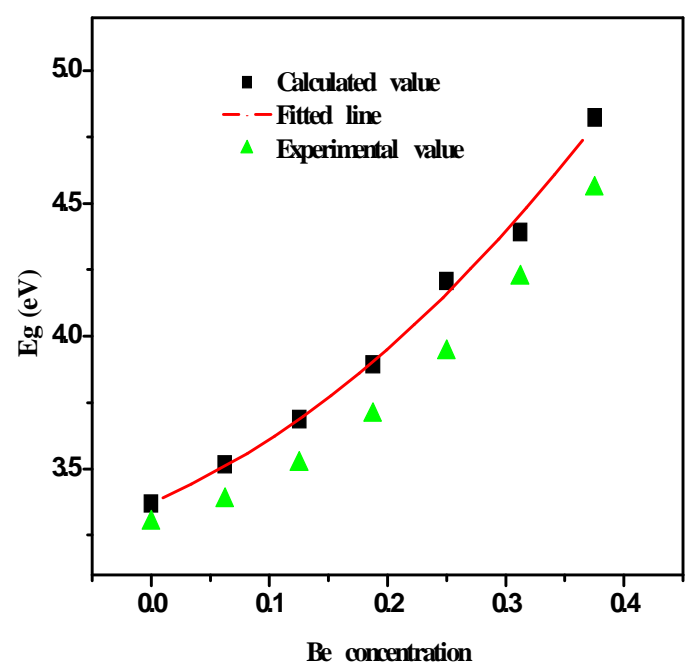

Fig.4 The calculated band-gaps of $\mathrm{Be}_{x} \mathrm{Zn}_{1-x} \mathrm{O}$ alloys dependent on Be concentration.

Fig.4 shows the calculated band-gaps of $\mathrm{Be}_{x} \mathrm{Zn}_{1-x} \mathrm{O}$ alloys dependent on Be concentration for further analysis, along with the available experimental values ${ }^{[19]}$. The bowing parameter were calculated by the following definition,

$$
E_{g}(x)=x \cdot E_{g}(\mathrm{BeO})+(1-x) \cdot E_{g}(\mathrm{ZnO})-b \cdot x \cdot(1-x)
$$

Where $E_{\mathrm{g}}(\mathrm{BeO})$ and $E_{\mathrm{g}}(\mathrm{ZnO})$ are the calculated band-gaps of $\mathrm{BeO}$ and $\mathrm{ZnO}, E_{\mathrm{g}}(x)$ are the band-gaps of $\mathrm{Be}_{x} \mathrm{Zn}_{1-x} \mathrm{O}$ alloys, $b$ is the band-gap bowing parameter. We fitted the calculated band-gaps in Fig.(4) by quadratic equation, and a bowing parameter of about $5.2 \mathrm{eV}$ is obtained for the $\mathrm{BeZnO}$ alloys, this value is very close to the theoretical value of $5.6 \mathrm{eV}$ by Ding et al. ${ }^{[13]}$, and is also not far from the experimental value of $6.32 \mathrm{eV}$ by J.H.Yu et al. ${ }^{[18]}$

To examine the relative stability of $\mathrm{Be}_{x} \mathrm{Zn}_{1-x} \mathrm{O}$ alloys, the formation enthalpies of mixing were calculated by taking the difference in total energy between the $\mathrm{Be}_{x} \mathrm{Zn}_{1-x} \mathrm{O}$ alloys and the weighted sum of the constituents $\mathrm{BeO}$ and $\mathrm{ZnO},{ }^{[20]}$ 


$$
\Delta H(x)=E_{t o t}\left(\mathrm{Be}_{x} \mathrm{Zn}_{1-x} \mathrm{O}\right)-\left[x \cdot E_{t o t}(\mathrm{BeO})+(1-x) \cdot E_{t o t}(\mathrm{ZnO})\right]
$$

Where $E_{\text {tot }}\left(\mathrm{Be}_{x} \mathrm{Zn}_{1-x} \mathrm{O}\right), E_{\text {tot }}(\mathrm{BeO})$ and $E_{\text {tot }}(\mathrm{ZnO})$ are the total energies of $\mathrm{Be}_{x} \mathrm{Zn}_{1-x} \mathrm{O}, \mathrm{BeO}$ and $\mathrm{ZnO}$ supercells. With $\mathrm{Be}$ concentration increasing, the $\mathrm{Be}_{x} \mathrm{Zn}_{1-x} \mathrm{O}$ alloys exhibits a net mixing enthalpy increase, higher formation enthalpies imply it is more difficult for higher Be doping level, which is consistent with the fact the intermediate Be concentration $(x \sim 0.5)$ will possibly result in phase separation for BeZnO alloys. ${ }^{[12]}$

\section{Conclusions}

In this study, we employed $\mathrm{Be}_{\mathrm{n}} \mathrm{Zn}_{16-\mathrm{n}} \mathrm{O}_{16}$ supercells and adopted DFT $+U$ method to investigate the structural and electronic properties of $\mathrm{BeZnO}$ alloys, the $U_{\mathrm{o}, \mathrm{p}}=10.2 \mathrm{eV}$ for O $2 \mathrm{p}$ and $U_{\mathrm{Zn}, \mathrm{d}}=1.4 \mathrm{eV}$ for $\mathrm{Zn} 3 \mathrm{~d}$ were obtained as the Hubbard $U$ values. Using this $U$ values the calculated band-gaps of $\mathrm{ZnO}$ and $\mathrm{BeO}$ are $3.369 \mathrm{eV}$ and $10.582 \mathrm{eV}$, respectively, which are well consistent with the experimental values of $3.37 \mathrm{eV}$ and $10.6 \mathrm{eV}$. The lattice constant $a$ and $c$, total energies, band-gaps as well as formation enthalpies were calculated for $\mathrm{Be}_{x} \mathrm{Zn}_{1-x} \mathrm{O}$ alloys with Be concentration varying from 0 to 0.375 . The lattice constants have very small deviation from experimental values and comply with the Vegard's law well. For the band-gaps of BeZnO alloys, a bowing parameter of about 5.2eV is obtained, which is close to the theoretical value by others and is also not far from the experimental values. For formation enthalpies of $\mathrm{Be}_{x} \mathrm{Zn}_{1-x} \mathrm{O}$ alloys, they exhibit a net increase with Be concentration increasing, higher formation enthalpies imply it is more difficult for higher Be doping level.

\section{Acknowledgements}

This work was financially supported by Science and Technology Program of Guangdong Province (2015B010112002, 2014B050505020), Science and Technology Program of Guangzhou City (2016201604030035), for which the authors are grateful.We also acknowledge R\&D Center for Semiconductor Lighting of Chinese Academy of Sciences providing us the use of CASTEP simulation program.

\section{References}

[1] H.Cao, Y.Ling, J.Y.Xu, C.Q.Cao, and P.Kumar, Phys. Rev. Lett. Vol.86 (2001), p.4524

[2] Mingxia Qiu, Yinzhu Zhang, Zhizhen Ye, Haiping He, Haiping Tang, Xiuquan Gu, Liping Zhu and Binghui Zhao, J. Phys. D: Appl. Phys.Vol.40 (2007), p.3229

[3] A. Y. Polyakov, N. B. Smirnov, A. V. Govorkov, E. A. Kozhukhova, A. I. Beloqorokhov, A.V. Markov,H.S.Kim, D.P. Norton, and S.J.Pearton, J. Electrochem. Soc.,Vol.154 (2007), p.825

[4] R. Thangavel, M. Rajagopalan, J. Kumar, Solid State Communications Vol.137 (2006) p.507

[5] Yonghong Hu, Bo Cai, Ziyu Hu, Yanli Liu, Shengli Zhang, Haibo Zeng,Current Applied Physics Vol.15 (2015) p.423

[6] L.N. Bai,B.J. Zheng, J.S. Lian, Q. Jiang, Solid State Sciences Vol.14 (2012) p.698

[7] S. Gowrishankar,L.Balakrishnan,N.Gopalakrishnan, Ceramics International Vol.40(2014) p.2135

[8] D.P.Xiong, X.G.Tang, Q.X.Liu, Vacuum,Vol.89 (2013) p.254

[9] X. L. Du, Z. X. Mei, Z. L. Liu, Y. Guo, T. C. Zhang, et. al., Adv. Mater. Vol.21(2009) p.4625.

[10] Y.R. Ryu, T.S. Lee, H.W. White, J. Crystal Growth Vol.261 (2004) p.502.

[11] Ryu Y R, Lee T S, Lubguban J A, White H W, et. al., Appl. Phys. Lett. Vol.88(2006) p.241108.

[12] Mingming Chen, Yuan Zhu, , Longxing Su, et al., Appl. Phys. Lett.Vol.103 (2013), p.072104

[13] R.W. Godby, M. Schluter, L.J. Sham, Phys. Rev. B Vol.36 (1987) p.6497.

[14] S. F. Ding, G. H. Fan, S. T. Li, K.Chen, and B.Xiao, Phys. B Vol.394 (2007) p.127.

[15] X. Ma, Y. Wu, Y. Lu, J. Xu, Y. Wang, Y. Zhu, J. Phys. Chem. C Vol.115 (2011) p.16963.

[16] X. Ma, B. Lu, D. Li, R. Shi, C. Pan, Y. Zhu, J. Phys. Chem. C Vol.115 (2011) p.4680.

[17]M.D. Segall, P.J.D. Lindan, M.J. Probert, C.J. Pickard, P.J. Hasnip, S.J. Clark, M.C. Payne, J. 
Phys. Condens. Matter Vol.14 (2002) p.2717.

[18] R.M. Sheetz, I. Ponomareva, E. Richter, A.N. Andriotis, M.Menon, Phys. Rev. B Vol.80 (2009) p.195314.

[19] J. H. Yu, J.H.Kim, H.J.Yang, T.S.Kim,T.S.Jeong, C.J. Youn, K.J. Hong, J Mater Sci (2012) Vol.47:p.5529

[20] R. de Paiva, J.L.A. Alves, R.A. Nogueira, et. al, Mater. Sci. Eng. B Vol.93 (2002) p.2 